\title{
PESQUISA DE CONSUMO DE CARNE BOVINA, PRODUTOS CÁRNEOS, HAMBÚRGUER E ALIMENTOS FUNCIONAIS
}

\author{
BEEF MEAT, MEAT PRODUCTS, HAMBURGER, FUNCTIONAL \\ FOOD CONSUMER RESEARCH
}

\author{
Natália Grando Vessoni ${ }^{1}$, Allan Fabro Piaia' ${ }^{1}$, Daniela Miotto Bernardi² \\ ${ }^{1}$ Nutricionista. Graduada pelo Centro Universitário FAG, Cascavel - PR. \\ 2 Nutricionista. Docente do Centro Universitário FAG, Cascavel - PR. Nutricionista Doutora em \\ Alimentos e Nutrição. \\ * Autor correspondente: danimiottober@gmail.com , https://orcid.org/0000-0001-9019-3835
}

\begin{abstract}
RESUMO
Introdução: O hambúrguer é um tipo produto cárneo que, em geral, tem elevado teor de gordura, entretanto, seu processo de fabricação permite que reformulações, como a adição de fibras, sejam feitas a fim de que o produto apresente melhores características nutricionais, assim como, propriedades funcionais. Neste contexto, 0 presente trabalho teve como objetivo realizar uma pesquisa de consumo de produtos cárneos e hambúrgueres, e verificar o conhecimento da população sobre alimentos funcionais e fibras. Métodos: A pesquisa continha 18 questões e foi realizada com 505 participantes, por meio do Google Formulários online. Resultados: Verificou-se um maior consumo de carne bovina e 68,7\% dos participantes relataram ser consumidores frequentes de hambúrguer. Os motivos mais apontados pelos consumidores para consumir hambúrguer foram sabor e a praticidade. Para $83,2 \%$ dos participantes o hambúrguer é um produto com grande quantidade de gordura, portanto necessita de uma formulação mais saudável. Em relação às fibras e alimentos funcionais, a maioria relatou que acredita que podem trazer benefícios para a saúde. Conclusão: Diante disto, a pesquisa demonstra um interesse da população pelo o aumento do consumo de alimentos funcionais e que o desenvolvimento de um hambúrguer com uma formulação mais saudável pode ser bem aceito pela população. Palavras-chave: Carnes. Produtos cárneos. Hambúrguer. Fibras. Alimentos
\end{abstract} funcionais.

\section{ABSTRACT}

Introduction: The hamburger is a type of meat product that, in general, has a high level of grease. However, its production process allows that reformulations, such as fiber addition, happens in order to present a product with better nutritional features, as well as, functional benefits. In this context, the present study has as objective make a consumer research of meat products and hamburgers and verify the population knowledge about functional food and fibers. Method: The research contained 18 questions and 505 people attended to it through Google. Results: It was found a big consume of beef meat and $68,7 \%$ of the participants reported that they frequently consume hamburger. The most pointed reason for the consumers was flavor and convenience. For $83,2 \%$ of the participants, the hamburger is a product with a big quantity of grease, which is why it needs a healthier reformulation. With regards to the fibers and functional food, the majority reported that they believe it can bring more health benefits. Conclusion: Therefore, the research shows that the population is interested on the increasement of functional foods and that the development of an hamburger with a healthier formula can be well accepted by the population. 
Keywords: Meats. Meat products. Hamburger. Fibers. Functional foods.

\section{INTRODUÇÃO}

A carne é um alimento que apresenta alta quantidade de proteínas de elevado valor biológico e boa digestibilidade para o organismo, além disso, atendem as necessidades de aminoácidos essenciais e nitrogênio total, necessários para a síntese proteica. Por outro lado, é um alimento com alto teor de gordura, sendo essa, em sua maioria, saturada quando se trata de carne bovina (PIRES et al., 2006).

Devido ao alto teor de gordura, especialmente as gorduras saturadas, o consumo frequente de produtos cárneos processados, pode estar ligado ao desenvolvimento de obesidade e de doenças cardiovasculares (SANTOS et al., 2011; CONDE e BORGES, 2011), uma vez que a ingestão elevada de gordura resulta em aumento dos níveis séricos de colesterol total e LDL, o que em longo prazo pode ocasionar o desenvolvimento da aterosclerose (ABADI e BUDEL, 2014). Estes efeitos são potencializados pela baixa ingestão de alimentos ricos em fibras e ao sedentarismo (SANTOS et al., 2013).

Pesquisas de consumo alimentar estão sendo utilizadas como ferramentas para analisar o estado de saúde da população, seus hábitos alimentares, e na identificação de riscos ou carências nutricionais (GOMES et al., 2015). Assim, também é possível fornecer meios de controle para o desenvolvimento de algumas patologias e estimar o consumo alimentar, para então traçar um perfil nutricional de determinada população e promover a educação nutricional (GOMES et al., 2015).

Ao longo dos anos, a população, principalmente os jovens, vem optando por refeições de rápido preparo, aumentando assim, o consumo de alimentos industrializados e ricos em gorduras saturadas. Dentre estes alimentos estão os lanches rápidos, encontrados facilmente em lanchonetes, como o hambúrguer (SILVA et al., 2011).

De acordo com o Regulamento Técnico de Identidade e Qualidade, o hambúrguer é um alimento feito de carne moída de diferentes espécies, onde se pode usar a gordura para dar maior estabilidade no produto, especiarias e demais ingredientes, que depois deve ser moldado e, se necessário, passar por um adequado processo tecnológico. Seu teor de gordura deve ser no máximo de $23 \%$, no mínimo $15 \%$ de proteínas e $3 \%$ de carboidratos totais (BRASIL, 2000).

Considerando que o consumo de hambúrguer é frequente e apreciado pela a maioria das pessoas, e que ele possui um alto teor de gordura, este produto merece uma atenção em relação à tecnologias que busque reduzir seu teor de gordura. As fibras, especificamente as solúveis, possuem a capacidade de formar géis que estabilizam o produto, podendo ser usadas como substitutos de gordura em alimentos (OLIVEIRA et al., 2013).

As fibras são compostas de polímeros de carboidratos que resistem à ação de enzimas do sistema digestório, podendo ser fermentadas no cólon. Como ingrediente alimentar, além da capacidade de atuarem como substitutas de gordura no produto, também possuem propriedades fisiológicas funcionais, são benéficas para um bom funcionamento do intestino, para melhorar o sistema imunológico, diminuir peso corporal juntamente com uma dieta balanceada, entre outros benefícios (BERNAUD e RODRIGUES, 2013).

Atualmente, os alimentos funcionais estão em alta no mercado. Entende-se por alimento funcional aqueles alimentos que têm como finalidade não somente o 
bem-estar e a nutrição básica do organismo, mas também a redução de riscos de doenças (OLIVEIRA et al., 2013).

Além disso, devem ser alimentos que promovem benefícios para o estado físico e psíquico dos indivíduos. Dentre suas características, estão alimentos que apresentam componentes naturais, biofortificados e devem conter fontes científicas comprovando sua funcionalidade (SANTOS, 2011).

Porém, muitas pessoas desconhecem os benefícios desses alimentos ou acabam se apegando a informações sem base científica quando o assunto é alimentação. A pesquisa Foodtrends Brasil 2020 realizada pelo sistema Fiep e Ibope (2010) constatou que os principais meios de informação sobre a importância dos alimentos são os programas de TV e, só então, as informações dos médicos e nutricionistas.

Nesse contexto, o objetivo do presente trabalho foi a realização de uma pesquisa de consumo de carne bovina e produtos cárneos, com foco principal no hambúrguer. Também foi verificado o conhecimento sobre os benefícios das fibras, assim como o consumo de alimentos funcionais, modificados e/ou enriquecidos.

\section{METODOLOGIA}

\subsection{CRITÉRIOS ÉTICOS E POPULAÇÃO}

Para a realização da pesquisa de consumo foram atendidos todos os procedimentos éticos necessários para a coleta de dados. A pesquisa foi realizada com 505 indivíduos de ambos os gêneros, de idades entre 18 e 57 anos, que foram convidados a responder um questionário composto por 18 questões fechadas. Antes de responder ao questionário, os participantes foram convidados a ler o termo de consentimento livre e esclarecido, como consta no APÊNDICE A.

\subsection{APLICAÇÃO DO QUESTIONÁRIO}

O questionário foi composto por 18 perguntas de múltipla escolha. O mesmo foi disponibilizado por meio da ferramenta online do Google chamado de Google Formulários, e solicitado que o participante fizesse a leitura e respondesse, sem qualquer constrangimento. As questões foram divididas em:

A) Perguntas referentes à apresentação do indivíduo, como idade, gênero, cor da pele ou raça e renda mensal aproximada, a fim de traçar um perfil do participante;

B) Ao consumo de carnes e produtos cárneos, e a frequência do consumo destes alimentos;

C) A frequência e motivação do consumo de hambúrguer, assim como sobre a quantidade de gorduras presentes neste produto;

D) Ao conhecimento do participante sobre a importância da redução de gorduras na dieta;

E) Aos atributos que são observados no alimento no momento da compra e os meios de comunicação em que o participante recebe mais informações sobre os produtos alimentícios;

F) Perguntas referentes ao consumo de fibras, alimentos enriquecidos e funcionais, assim como o conhecimento das fibras de soja, pectina e farinha de aveia, e intenção de consumo de alimentos enriquecidos com essas fibras. Todas as respostas foram mantidas em sigilo, usadas somente para fins científicos. 


\subsection{ANÁLISE DOS DADOS:}

Os dados obtidos na pesquisa foram tabulados na própria ferramenta online do Google e foram observados os resultados através de gráficos de comparação.

\section{RESULTADOS E DISCUSSÕES}

\subsection{PERFIL DOS PARTICIPANTES}

A pesquisa de consumo foi realizada com 505 indivíduos, de 18 a 57 anos. Dentre os participantes, 19 foram excluídos da pesquisa, pois não aceitaram o termo de consentimento ou apresentaram idade inferior a 18 anos. Os participantes foram $87,3 \%$ do gênero feminino, com idades de 18 a 57 anos, e $12,7 \%$ do gênero masculino, com idades de 18 a 54 anos.

As informações dadas sobre cor da pele ou raça e renda mensal dos participantes entrevistados estão descritas na Figura 1.

Figura 1. Cor/raça e renda mensal dos participantes da pesquisa

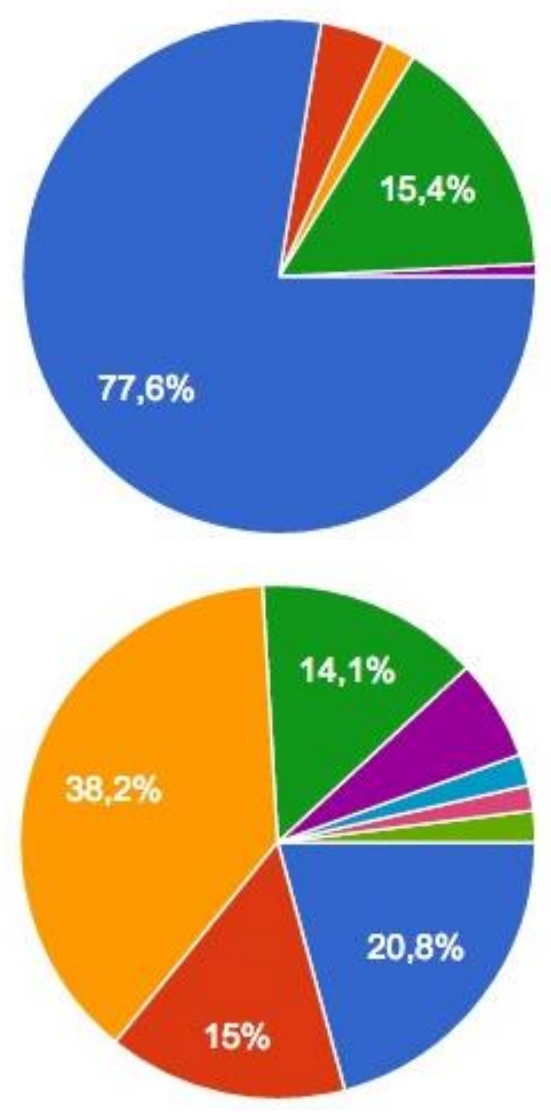

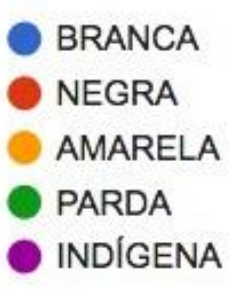

Nenhuma renda.

Até 1 salário mínimo (até $\mathrm{R} \$ 937,00$ ).

De 1 a 3 salários mínimos (de RS 937,00 até $\mathrm{R} \$ 2.811,00$ ).

De 3 a 6 salários mínimos (de RS $2.811,00$ até $\mathrm{R} \$ 5.622,00$ ).

De 6 a 9 salários mínimos (de R\$ $5 \ldots$

De 9 a 12 salários mínimos (de R\$...

De 12 a 15 salários mínimos (de R\$..

Mais de 15 salários mínimos (mais...

\subsection{CONSUMO DE CARNES, PRODUTOS CÁRNEOS E HAMBÚRGUERES}

A primeira pergunta refere-se ao tipo de carne consumida pelos participantes. De acordo com a pesquisa, apresenta-se a carne bovina como a mais consumida, apresentando um valor de $64,4 \%$ dos participantes. Em segundo lugar está a carne de aves, sendo $31,3 \%$ dos participantes. As demais carnes são de peixe $(2 \%)$, carne suína (1\%) e outros tipos de carnes $(1,4 \%)$. 
O consumo de carne bovina também prevalece em relação aos outros tipos de carnes em diferentes estudos. Uma pesquisa feita com estudantes de medicina veterinária em Uberlândia (MG) apontou maior consumo de carne bovina. De acordo com esta pesquisa, Silveira et al. (2016) aponta que $68,67 \%$ dos estudantes relataram o maior consumo desta carne, seguindo de frango (28,67\%), peixe $(2 \%)$ e carne suína $(0,67 \%)$. Ainda, Bezerra et al. (2007) cita em sua pesquisa que a maioria dos participantes também consomem, preferencialmente, a carne bovina $(47,75 \%)$, $21,75 \%$ preferem a carne de frango, $17,5 \%$ a suína e $13 \%$ a de peixe. Por sua vez, Assoni e Bernardi (2015) apresenta que 61,9\% dos participantes de seu estudo relataram preferir a carne bovina e $28 \%$ a carne de frango. Os demais foram divididos em carne suína e carne de peixe, como sendo as menos consumidas, portanto, estes dados corroboram com o presente estudo.

Além dos tipos de carnes consumidos e, devido ao consumo de carne bovina ser o enfoque da pesquisa, os participantes foram questionados sobre a frequência do consumo desta carne. Em torno de $53,5 \%$ relataram consumir duas vezes ou mais por semana, $28,7 \%$ relataram consumir carne bovina diariamente, $10,5 \%$ uma vez por semana, $3,2 \%$ a cada 15 dias, $2 \%$ uma vez por mês e $2,2 \%$ dos participantes relataram não consumir carne bovina.

Em relação aos motivos para o consumo da carne bovina, o habito familiar e o sabor destacam-se. Na Figura 2 são apresentados os demais motivos apontados pelos consumidores.

Figura 2. Motivos para o consumo de carne bovina

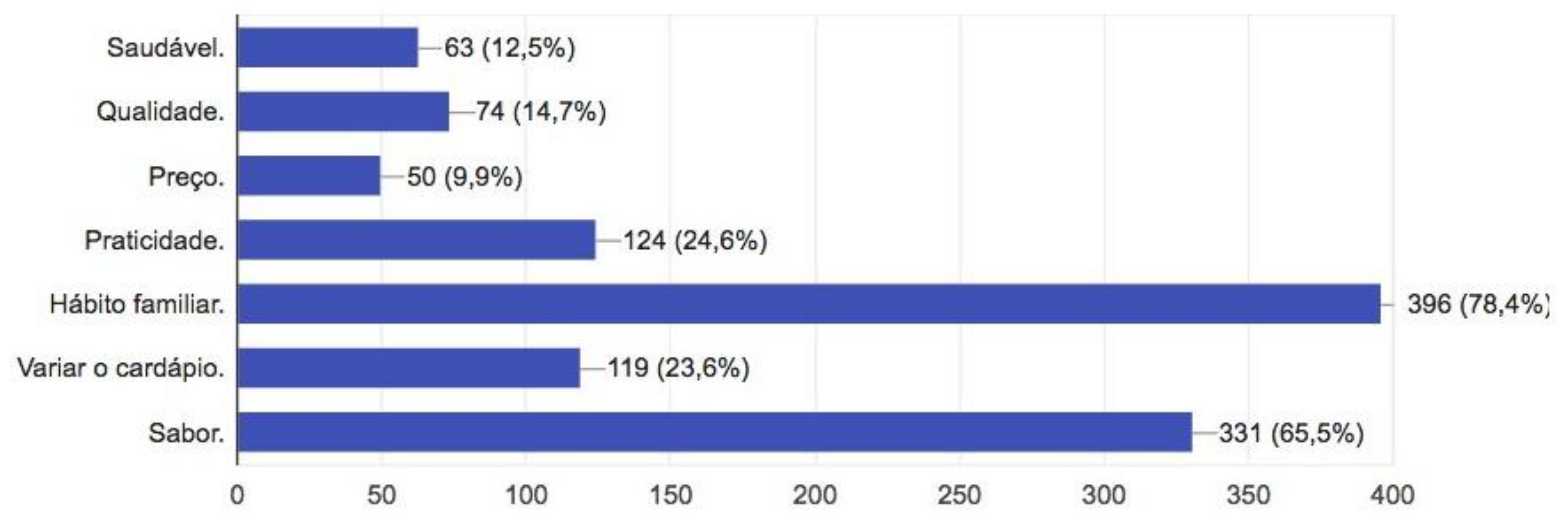

A frequência do consumo de carne bovina foi avaliada em outra pesquisa, na cidade de Pelotas (RS). De acordo com Assunção et al. (2012), o consumo diário da carne foi de $43 \%$ de uma amostra de 4.325 adolescentes do município, 31,3\% relataram consumir de 4 a 6 vezes por semana, 21,7\% de 1 a 3 vezes por semana e $4 \%$ relataram consumir menos que 1 vez por semana.

Um estudo de Slattery et al. (1991) constatou um impacto negativo no consumo elevado de carne bovina, onde foi observado que indivíduos que consumiam maior quantidade desta carne apresentaram também um maior consumo de gordura, proteína e álcool e, em contrapartida, menor consumo de fibras, vitaminas e alguns minerais, como o cálcio.

Eichholzer et al. (2000) apresentou resultados semelhantes em seu estudo, onde constatou que indivíduos que ingeriam carne bovina frequentemente apresentaram maior consumo de bebidas alcoólicas e também apresentavam sobrepeso ou obesidade. 
a Figura 3.

O consumo de produtos cárneos também foi avaliado, como demonstra

Figura 3. Produtos cárneos consumidos

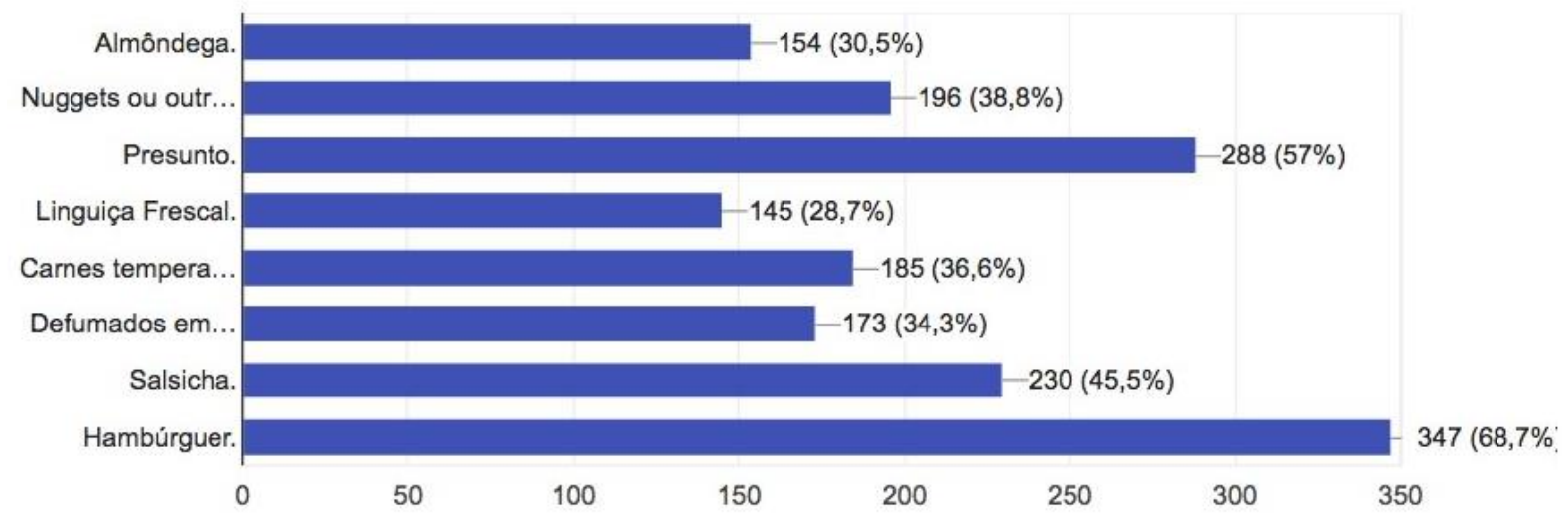

De acordo com Oliveira et al. (2013), a população busca, atualmente, alimentos prontos, que não demandam muito tempo de preparo e, frequentemente, industrializados. Os produtos cárneos tornam-se alimentos frequentes nos hábitos alimentares da população, devido a esta praticidade. Porém, estes alimentos podem apresentar grandes quantidades de gorduras, aditivos químicos e sódio, sendo válido um controle no consumo desses produtos.

Para Trevisan et al. (2016) o mercado alimentício vem se preocupando em oferecer produtos cárneos com redução de gordura e sódio para quem busca hábitos alimentares mais saudáveis, ou até mesmo na prevenção de algumas doenças.

Dentre os itens avaliados, o hambúrguer se sobressaiu em relação aos demais produtos cárneos, seguido de presunto, salsicha e demais produtos. A frequência do consumo de hambúrguer foi avaliada, onde a maioria dos participantes $(29,5 \%)$ relatou consumir apenas uma vez por mês, $28,5 \%$ a cada 15 dias, $28,1 \%$ uma vez por semana, $5,5 \%$ duas vezes ou mais por semana, $0,6 \%$ diariamente e $7,7 \%$ relataram não consumir hambúrguer.

Segundo Oliveira et al. (2013), a preferência pelo consumo de hambúrguer se torna maior devido ao produto ser de fácil preparo, promover saciedade, além de possuir nutrientes benéficos para o organismo. Isto fica claro na presente pesquisa (Figura 4), onde $41,8 \%$ dos participantes relataram a praticidade como um dos motivos principais para o consumo desse produto, além do sabor, onde $66,1 \%$ dos participantes relataram ser o motivo principal. Hautrive et al. (2008) também ressalta a praticidade como motivo principal no consumo do hambúrguer pela população, além de causar saciedade, sendo um produto frequentemente consumido devido a estes fatores. 
Figura 4. Motivos para o consumo de hambúrguer

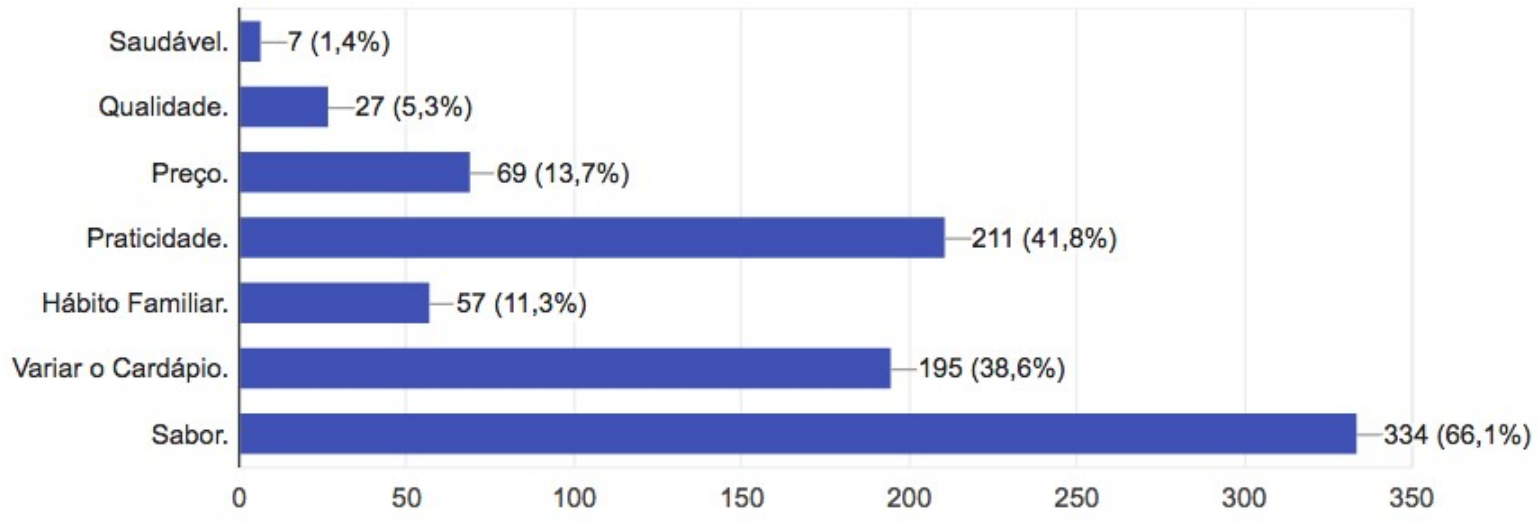

Quando questionados sobre se o hambúrguer apresenta grande quantidade de gordura, $83,2 \%$ dos participantes acreditam que sim, 13,1\% acham que não e 13,8\% preferiram não opinar. Oliveira et al. (2013) cita que os produtos cárneos, como o hambúrguer, apresentam em torno de 20 a 30\% de gordura. Se consumido em excesso e a longo prazo, este excesso pode vir a desencadear doenças crônicas como, dislipidemias, obesidade, diabetes e hipertensão.

Oliveira et al. (2014) em outro estudo apresenta que a diminuição do conteúdo de gordura melhoraria a qualidade nutricional do hambúrguer, porém atribuições como sabor, textura e aroma poderiam ser prejudicados, pois a gordura é fundamental para tais atribuições em um produto.

Seabra et al. (2002) diz que ao longo dos anos as industrias vêm se preocupando em reduzir quantidades exageradas de gorduras no produto, reduzindo o valor de gordura de 20 a $30 \%$ para $10 \%$. Porém, como mencionado no estudo supracitado, quesitos como a textura e rendimento do produto podem ser modificados com a redução de gordura, além da aceitação limitada relatada pelos consumidores, sendo um problema para a indústria alimentícia.

\subsection{VISÃO DO CONSUMIDOR SOBRE A PRESENÇA DE GORDURA NOS ALIMENTOS \\ O excesso de gordura saturada presente em alimentos de origem animal,} como as carnes, vem preocupando alguns pesquisadores devido ao seu efeito negativo para o organismo. Lottenberg (2009) ressalta que este alto consumo é uma predisposição para o desenvolvimento de doenças cardiovasculares, além de atuarem como agentes inflamatórios, podendo desencadear doenças como obesidade, diabetes e aterosclerose.

$\mathrm{Na}$ presente pesquisa, quando questionados sobre o hábito do consumo de gordura, 57,8\% dos participantes relataram não ingerir alimentos com redução de gorduras. Destes participantes, apenas 39,8\% relataram o hábito de preferir alimentos com menos gorduras e 2,4\% optaram por não opinar. Em relação à importância da ingestão de produtos com baixa quantidade de gordura para a saúde, 93,5\% dos participantes acreditam que é importante reduzir a quantidade de gordura dos produtos ingeridos diariamente, $4 \%$ acham que não é importante esta redução e 2,6\% não quiseram opinar.

Devido ao aumento de doenças relacionadas ao consumo exagerado de gordura, Hautrive et al. (2008) acredita que os consumidores estão tendo percepções 
que, juntamente com hábitos inadequados, uma dieta composta por um excesso de gordura no organismo pode vir a desencadear essas patologias.

White et al. (2013) também cita em sua pesquisa que a redução do consumo de gorduras pode influenciar a prevenção de doenças cardiovasculares, assim como diminuir as chances de desenvolver uma resistência à insulina e controlar o excesso de peso.

\title{
3.4 ATRIBUTOS IMPORTANTES NA HORA DA COMPRA
}

No momento da compra muitos atributos são considerados pelos consumidores, e dentre os atributos avaliados na presente pesquisa (Figura 5), a qualidade se sobressaiu, uma vez que $50,3 \%$ dos participantes relataram que a qualidade é determinante na escolha. Outros atributos também foram apontados, 0 atributo preço $(28,7 \%)$ e se o alimento é saudável $(11,1 \%)$. Os resultados corroboram com os obtidos por Assoni e Bernardi (2015), onde o atributo qualidade também foi o mais votado (38\%) pelos participantes, seguido de alimento saudável (21\%) e por último o preço do produto (17\%).

Figura 5. Atributos importantes na hora da compra

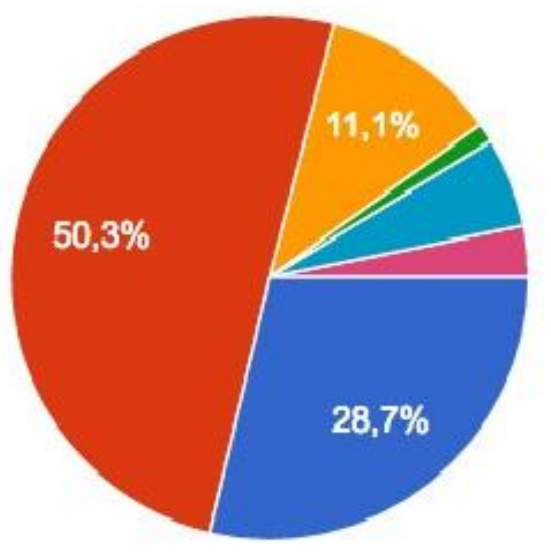

\author{
- Preço. \\ Qualidade. \\ Saudável. \\ Seu peso corporal. \\ Embalagem. \\ Rotulo nutricional. \\ Tamanho da porção.
}

\subsection{CONSUMO DE FIBRAS E ALIMENTOS FUNCIONAIS}

De acordo com Macedo et al., (2012), as fibras são alimentos funcionais que atuam com fins terapêuticos no organismo, sendo fundamentais para a prevenção de algumas patologias, juntamente com um estilo de vida saudável. De acordo com este estudo, as fibras também atuam como substâncias reguladoras e auxiliam no bom funcionamento do trânsito intestinal.

É possível observar que a maioria das pessoas na presente pesquisa conhecem os benefícios das fibras $(67,1 \%)$, número este maior que o encontrado por Assoni e Bernardi (2015), onde foi constatado que apenas $49 \%$ dos participantes disseram conhecer benefícios das fibras.

Quanto ao hábito de consumir alimentos modificados ou enriquecidos, a maioria dos participantes $(57,8 \%)$ da pesquisa relatou não ter o hábito de consumir esses produtos, enquanto que $33,9 \%$ relatou consumir produtos modificados e enriquecidos.

Oliveira (2008), por outro lado, acredita que os consumidores estão cada vez mais interessados em consumir alimentos modificados/enriquecidos e alimentos funcionais. Isto se deve ao aumento do número de pessoas com um desenvolvimento 
precoce de doenças crônicas, fazendo com que a população se preocupe mais e acabam sensibilizados com as vantagens que esses alimentos proporcionam.

O conhecimento sobre alimentos funcionais também fez parte da presente pesquisa, e verificou-se que $88,7 \%$ dos participantes acreditam que estes alimentos podem trazer benefícios para a saúde, 0,8\% acreditam que não e 10,5\% não quiseram opinar sobre o tema. Resultados semelhantes foram obtidos por Ferrão (2012), onde este cita que $85 \%$ dos consumidores acreditam que alimentos funcionais podem sim trazer benefícios para a saúde e, consequentemente, diminuir as chances de desenvolvimento de algumas doenças. Assoni e Bernardi (2015) também citam em sua pesquisa que, $77 \%$ dos participantes acreditam que os alimentos funcionais são benéficos para a saúde e ainda que $44 \%$ de sua amostra acredita que, no futuro, os alimentos funcionais vão substituir alguns medicamentos na prevenção e controle de algumas doenças. Quando comparado o presente estudo com o de Assoni e Bernardi (2015), pode-se observar que em apenas dois anos houve o aumento do conhecimento sobre o tema pela população.

Uma pesquisa feita pelo Foodtrends Brasil 2020 (FIEP/IBOPE, 2010) constatou que $33 \%$ dos participantes acreditam totalmente que alimentos funcionais podem trazer benefícios à saúde e $51 \%$ acreditam parcialmente.

Os benefícios desses alimentos são ressaltados no estudo feito por Vidal et al. (2012), onde afirma que alimentos funcionais atuam como antioxidantes, diminuem os níveis de colesterol sérico, diminuindo assim os riscos de desenvolvimento da aterosclerose, apresentam efeitos anti-inflamatório, controle da glicemia, entre outros.

Os participantes também foram questionados sobre o conhecimento de determinadas fibras. A mais conhecida foi a farinha de aveia, onde $91,5 \%$ dos participantes relataram ter um conhecimento sobre esta e $8,5 \%$ disseram não conhecer. A segunda mais conhecida foi a fibra de soja, onde $51,3 \%$ dos indivíduos relataram conhecer esta fibra e $48,7 \%$ não conhecem. Por último e menos conhecida ficou a pectina, onde grande maioria relata não conhecer esta fibra ( $80 \%)$, enquanto que $19,4 \%$ disseram conhecer e $0,6 \%$ dos participantes não quiseram opinar. Ainda, foram questionados se consumiriam as determinadas fibras (Figura 6).

Figura 6. Respostas dos consumidores sobre o consumo de pectina, fibra de soja e farinha de aveia

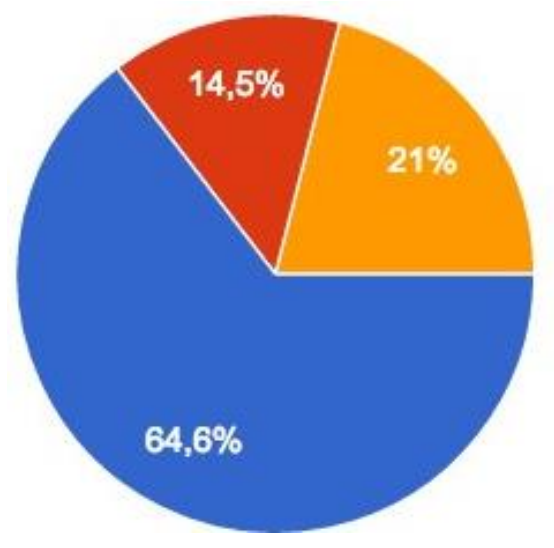

Sim.

Não.

Não quero opinar.

As fibras citadas na pesquisa são fibras solúveis, ou seja, fibras que são solúveis em água. Macedo et al., (2012) cita que a característica dessas fibras é a capacidade em formar gel quando entram em contato com a água e que podem ser utilizadas como substitutas de gordura. 


\subsection{FONTES DE INFORMAÇÕES DE PRODUTOS ALIMENTÍCIOS}

A Figura 7 mostra as principais fontes de informações de produtos alimentícios.

Figura 7. Principais fontes de informações de produtos alimentícios

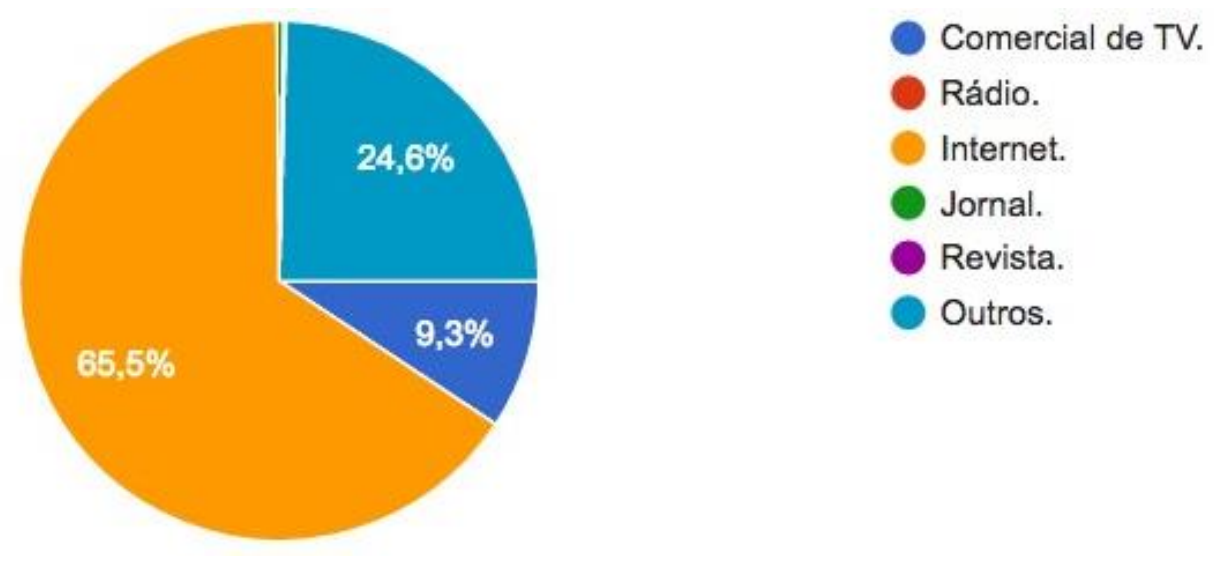

Os itens rádio e revista nem foram citados pelos participantes, e o jornal foi tido como o item menos votado, com $0,4 \%$, totalizando apenas 2 participantes da pesquisa. Segundo Santos (2011), os meios de comunicações são de grande importância na propagação de informações de cunho nutricional. Infelizmente, algumas dessas informações são inverídicas, onde seus ouvintes e leitores são sugestionados a acreditar, o que pode influenciar de forma negativa suas crenças e hábitos alimentares diários. Porém, essas informações também podem servir como um meio de educação nutricional para a população, quando propagadas de forma adequada.

De acordo com os resultados da pesquisa Foodtrends Brasil 2020, realizada pelo sistema Fiep e lbope (2010), os principais meios de informações sobre alimentos são a televisão (40\%), seguido da opinião de médicos e nutricionistas (20\%), internet (19\%), pessoas conhecidas e amigos (16\%), familiares e jornais (14\%), revistas (12\%) e $13 \%$ relataram não buscar informações.

Ferrão (2012), por outro lado, cita que os consumidores preferem acreditar em fontes científicas dadas por um profissional da saúde do que por meio de meios de comunicação, ou até mesmo por meio dos rótulos dos produtos.

\section{CONSIDERAÇÕES FINAIS}

De acordo com os resultados observados, a carne bovina é a carne mais consumida pelos participantes (duas vezes ou mais por semana) e o hambúrguer 0 produto cárneo mais consumido. Ainda, foi possível observar que o consumo deste produto é maior devido seu sabor e praticidade.

Em relação às fibras, a maioria dos participantes relatou conhecer os seus benefícios e acreditam que alimentos funcionais podem ser importantes para a saúde, porém mostrou-se que não há um costume de ingerir alimentos modificados e/ou enriquecidos pela maioria dos entrevistados.

A qualidade do produto foi considerada o atributo mais considerável pelos participantes na hora da compra, seguida de preço e só então por considerarem um alimento saudável. Isto pode ocorrer, dentre outros fatores, pela carência de educação 
nutricional que é passada para a população, estilo de vida e por questões socioeconômicas. Ainda, a maioria dos participantes relatou obter informações de produtos alimentícios pela internet, seguindo por outros meios de informação não identificados.

Neste contexto, considerando a necessidade e vontade dos indivíduos em melhorar seus hábitos alimentares, o desenvolvimento de um produto inovador, como um hambúrguer com menor teor de gordura, utilizando a fibra como substituta, teria um potencial de chegar às prateleiras dos mercados da população brasileira e ser bem aceito pela mesma, especialmente se a mídia certa for utilizada para propagação das informações e benefícios nutricionais deste produto.

\section{REFERÊNCIAS}

ABADI, L. B.; BUDEL, J. M. Aspectos clínicos laboratoriais das dislipidemias. Cadernos da Escola de Saúde, Curitiba, 5: 182-195 ISSN 1984-7041, 2014.

ASSONI, P. B.; BERNARDI, D. M. Pesquisa sobre consumo de carne suína, produtos processados e alimentos funcionais. Trabalho de Conclusão de Curso. Cascavel, PR. 2015

ASSUNÇÃO, M. C. F. et al. Consumo de carnes por adolescentes do Sul do Brasil. Rev. Nutr., Campinas, v. 25, n. 4, p. 463-472, Aug. 2012. http://dx.doi.org/10.1590/S1415-52732012000400004.

BERNAUD, F. S. R.; RODRIGUES, T. C. Fibra alimentar: ingestão adequada e efeitos sobre a saúde do metabolismo. Arq Bras Endocrinol Metab, São Paulo, v. 57, n. 6, p. 397-405, Aug. 2013 . http://dx.doi.org/10.1590/S0004-27302013000600001

BEZERRA, J. M. M. et al. Caracterização do consumidor e do mercado da carne suína na microrregião de Campina Grande, estado da Paraíba. Ciência Animal Brasileira, v. 8, n. 3, p. 485-493, jul./set. 2007.

BRASIL FOOD TRENDS 2020 / Federação das Indústrias do Estado de São Paulo, Instituto de Tecnologia de Alimentos. São Paulo; FIESP/ITAL, 2010. Disponível em <http://www.brasilfoodtrends.com.br/> Acesso em: 30 jun. 2017.

BRASIL. Ministério da Agricultura, Pecuária e Abastecimento. Instrução Normativa no 20, de 31 de julho de 2000. Regulamentos Técnicos de Identidade e Qualidade de Almôndega, de Apresuntado, de Fiambre, de Hamburguer, de Kibe, de Presunto Cozido e de Presunto. Diário Oficial da República Federativa do Brasil, Brasília, DF, 1 ago. 2000. Seção 1, p. 3-31.

CONDE, W. L.; BORGES, C. O risco de incidência e persistência da obesidade entre adultos Brasileiros segundo seu estado nutricional ao final da adolescência. Rev. bras. epidemiol., São Paulo, v. 14, supl. 1, p. 71-79, Sept. 2011. http://dx.doi.org/10.1590/S1415-790X2011000500008

EICHHOLZER M.; BISIG, B. Daily consumption of (red) meat or meat products in Switzerland: results of the 1992/93 Swiss Health Survey. Eur J Clin Nutr. 2000 Feb; 54(2):136-42. 
FERRÃO, M. L. C. Percepção dos consumidores portugueses sobre os alimentos funcionais. Eshte, Mestrado em Segurança e Qualidade Alimentar na Restauração. Estoril, Junho de 2012

GOMES, A. A.; PEREIRA, R. A.; YOKOO, E. M.. Caracterização do consumo alimentar de adultos por meio de questionário simplificado: contribuição para os estudos de vigilância alimentar e nutricional. Cad. Saúde Colet., Rio de Janeiro, 23 (4): 368-373. 2015. http://dx.doi.org/10.1590/1414-462X201500040055.

HAUTRIVE, T. P. et al . Análise físico-química e sensorial de hambúrguer elaborado com carne de avestruz. Ciênc. Tecnol. Aliment., Campinas , v. 28, supl. p. 95101, Dec. 2008.

LOTTENBERG, A. M. P. Importância da gordura alimentar na prevenção e no controle de distúrbios metabólicos e da doença cardiovascular. Arq Bras Endocrinol Metab, São Paulo, v. 53, n. 5, p. 595-607, July 2009 .http://dx.doi.org/10.1590/S0004-27302009000500012

MACEDO, T. M. B; SCHMOURLO, G.; VIANA, K. D. A. L. Fibra alimentar como mecanismo preventivo de doenças crônicas e distúrbios metabólicos. Revista UNI. Imperatriz (MA), ano 2, n.2 , p.67-77. janeiro/julho, 2012.

OLIVEIRA, D. F. et al. Alternativas para um produto cárneo mais saudável: uma revisão. Braz. J. Food Technol., Campinas, v. 16, n. 3, p. 163-174, Sept. 2013. http://dx.doi.org/10.1590/S1981-67232013005000021

.Farinha de linhaça dourada como substituto de gordura animal em hambúrguer de carne bovina com redução de sódio. Braz. J. Food Technol., Campinas , v. 17, n. 4, p. 273-282, Dec. 2014 . http://dx.doi.org/10.1590/1981-6723.0714

OLIVEIRA, H. P. S. O consumo de alimentos funcionais - atitudes e comportamentos. 2008. Dissertação - (Mestrado em ciências da comunicação, especialização em Markintg e comunicação estratégica) - Universidade Fernando de Pessoa, Porto, 2008

PIRES, C. V. et al. Qualidade nutricional e escore químico de aminoácidos de diferentes fontes proteicas. Ciênc. Tecnol. Aliment., Campinas, v. 26, n. 1, p. 179187, Mar. 2006 . http://dx.doi.org/10.1590/S0101-20612006000100029

SANTOS, F. L. Os alimentos funcionas na mídia: quem paga a conta. In: PORTO, CM., BROTAS, AMP., and BORTOLIERO, ST., orgs. Diálogos entre ciência e divulgação científica: leituras contemporâneas. Salvador: EDUFBA, 2011, pp. 199210. ISBN 978-85-232-1181-3.

SANTOS FILHO, R D. et al. I Diretriz sobre o consumo de gorduras e saúde cardiovascular. Arq. Bras. Cardiol., São Paulo , v. 100, n. 1, supl. 3, p. 140, Jan. 2013 . http://dx.doi.org/10.1590/S0066-782X2013000900001 
SEABRA, L. M. J. et al . Fécula de mandioca e farinha de aveia como substitutos de gordura na formulação de hambúrguer de carne ovina. Ciênc. Tecnol. Aliment., Campinas , v. 22, n. 3, p. 245-248, Dec. 2002 . http://dx.doi.org/10.1590/S0101-20612002000300008.

SILVA, J. A.; NÓBREGA, E. S.; COSTA, M. J. C. et al. Efeito do consumo de hambúrguer de carne de avestruz e hambúrguer bovino comercial em ratos jovens, pela análise de teores de colesterol total e frações lipoproteicas. Rev Inst Adolfo Lutz; 70(3):324-31; 2011.

SILVEIRA, A. C. P. et al. Estudantes de medicina veterinária como consumidores de carne suína em Uberlândia, MG. PUBVET, v.10, n.5, p.439-447, Mai., 2016.

SLATTERY, M. et al. Meat consumption and its associations with other diet and health factors in young adults: the CARDIA study. The American journal of clinical nutrition. $1991 \mathrm{Nov} ; 54(5): 930-5$.

TREVISAN, Y. C. et al. Efeito da adição de fibra de aveia sobre as propriedades físicoquímicas de hambúrguer cozido e congelado com redução de gordura e sal. Braz. J. Food Technol., Campinas, v. 19, e2015079, 2016 http://dx.doi.org/10.1590/1981-6723.7915

VIDAL, A. M. et al. A ingestão de alimentos funcionais e sua contribuição para a diminuição da incidência de doenças. Ciências Biológicas e da Saúde. Aracaju. v. 1, n.15, p. 43-52, out. 2012.

WHITE, P. A.. Secundo. et al. Modelo de obesidade induzida por dieta hiperlipídica e associada à resistência à ação da insulina e intolerância à glicose. Arq Bras Endocrinol Metab, São Paulo , v. 57, n. 5, p. 339-345, July 2013. http://dx.doi.org/10.1590/S0004-27302013000500002 